\title{
Phencyclidine-Induced Behavioral Sensitization
}

\author{
XIAOJUAN XU AND EDWARD F. DOMINO' \\ Department of Pharmacology, University of Michigan, Ann Arbor, MI 48109-0626
}

Received 23 April 1993

\begin{abstract}
XU, X. AND E. F. DOMINO. Phencyclidine-induced behavioral sensitization. PHARMACOL BIOCHEM BEHAV 47(3) 603-608, 1994. - Chronic administration of a psychomotor stimulant has been shown to produce progressively enhanced effects, a phenomenon called "reverse tolerance" or sensitization. The present study reexamined the effects of the daily injection of phencyclidine on locomotor activity and stereotypy in rats, and investigated whether drug-environment conditioning was necessary for the development of behavioral sensitization and whether $(5 R, 10 S)-(+)-5$-methyl-10,11-dihydro$5 H$-dibenzo[ $a, b]$ cyclohepten-5,10-imine hydrogen maleate (MK-801, dizocilpine) blocked behavioral sensitization to phencyclidine. Female Sprague-Dawley rats were used. Locomotor activity and stereotypy were measured automatically with the Digiscan system. The results confirmed an earlier finding that four daily injections of phencyclidine induced sensitization to both locomotor activity and stereotypy. The development of behavioral sensitization did not require drug-environment conditioning. Moreover, MK-801 did not block behavioral sensitization to phencyclidine. The results of the present study suggest that the neuronal mechanisms underlying sensitization to phencyclidine are different from those underlying sensitization to amphetamine and cocaine.
\end{abstract}

Phencyclidine (PCP) Reverse tolerance Behavioral sensitization Locomotor activity Stereotypy Dizocilpine (MK-801)

CHRONIC administration of a psychomotor stimulant has been shown to produce progressively enhanced behavioral effects, a phenomenon called sensitization or "reverse tolerance." Repeated injection of phencyclidine has been reported to produce different effects on locomotor activity, rearing, stereotypy, and ataxia. Phencyclidine can produce sensitization to locomotor activity, rearing, and stereotypy, but tolerance to ataxia. Several investigators have shown that sensitization to phencyclidine-induced locomotor activity in rodents develops after four daily systemic injections of $2.5,4,5$, or $10 \mathrm{mg} / \mathrm{kg}(1,5-7,19)$. The increase in locomotor activity was followed by decrease to day 1 levels over 14 days in a study by Castellani and Adams (2) using a dose of $4 \mathrm{mg} / \mathrm{kg}$ of phencyclidine given SC. Chronic administration of phencyclidine also produced sensitization to rearing behavior in most studies, and induced sensitization to stereotypy in some studies and no significant changes in others $(5-7,18)$. However, chronic administration of moderate doses of phencyclidine induced tolerance to ataxia $(2,12,19)$, but low or high doses $(6,12)$ did not significantly induce either tolerance or sensitization to ataxia.

When the administration of a psychomotor stimulant is repeatedly paired with a unique test environment, the development of sensitization to the locomotor stimulant effects can, at least partially, result from drug-environment conditioning
$(3,14,16)$. However, drug-environment conditioning alone cannot account for the development of behavioral sensitization to amphetamine (15). Furthermore, drug-environment conditioning is not necessary for the development of behavioral sensitization to amphetamine $(1,15)$. Phencyclidine exerts its effects through several different neurotransmitter mechanisms including dopamine. Four daily injections of amphetamine sensitized animals to the locomotor stimulant effects of phencyclidine, but four daily treatments with phencyclidine decreased the locomotor response to a challenge injection of amphetamine (5). Asymmetric cross-sensitization between amphetamine and phencyclidine suggests significant differences in the mechanisms underlying behavioral sensitization to these agents. Thus, the possibility exists that drugenvironment conditioning might account for the enhanced stimulant effects of chronic administration of phencyclidine.

Recent studies have demonstrated that behavioral sensitization to amphetamine and cocaine requires activation of the $N$-methyl-D-aspartate (NMDA) class of glutamate receptors because sensitization is blocked by MK-801, a noncompetitive NMDA receptor antagonist $(8,21)$. Karler et al. (9-11) further suggest that behavioral sensitization to amphetamine and cocaine involves a common mechanism that is activated via the NMDA component of glutamate receptors. Because rats sensitized to phencyclidine do not exhibit cross-sensitization to am-

\footnotetext{
${ }^{1}$ To whom requests for reprints should be addressed.
} 
phetamine, it is likely that amphetamine and phencyclidine sensitization occur via different neuronal mechanisms.

The present study reexamined the effects of daily administration of phencyclidine on locomotor activity and stereotypy, investigated whether drug-environment conditioning was necessary for the development of behavioral sensitization to phencyclidine, and examined whether MK-801 blocked phencyclidine sensitization in rats. The results confirmed an earlier finding that four daily injections of phencyclidine induced sensitization and that this effect did not involve conditioning to the testing situation; furthermore, MK-801 did not block this sensitization.

METHODS

\section{Subjects}

Female Sprague-Dawley rats, weighing 200-265 g, were used in this study. The animals were allowed at least 1 week of acclimatization upon arrival to the animal facilities. During this time, as well as during a subsequent experimental period, the rats were housed two or three per cage with free access to food and water in a rodent room with constant temperature, humidity, and a $12 \mathrm{~L}: 12$ D cycle (0700-1900 light).

\section{Apparatus}

Locomotor activity and stereotypy of each animal were measured with the Digiscan "Micro" system consisting of four mounting frames and one analyzer (Omnitech Electronics, Columbus, $\mathrm{OH}$ ). A mounting frame contained two parallel panels, one photocell panel with 16 infrared light beams spaced $2.54 \mathrm{~cm}$ apart, and one light beam detector panel. Each rat was placed in a transparent Plexiglas cage $(46 \times 24 \times 18$ $\mathrm{cm}$ ) within a mounting frame located in a sound-dampened chamber. The Digiscan system detected locomotor activity by counting interruptions of consecutive light beams caused by the animal moving from one location to another. Stereotypy was measured by counting repetitive interruptions of the same light beam produced by stereotyped activities, such as repetitive head movement. Data were automatically recorded and processed by the analyzer, and further transferred to and stored on a Macintosh IIsi computer.

\section{Drugs}

Phencyclidine, as the free base, was dissolved in $\mathrm{HCl}$ and saline $(0.9 \% \mathrm{NaCl})$ solution. The drug was then neutralized with $\mathrm{NaOH}$ to give a final $\mathrm{pH}$ of approximately 6.4. Phencyclidine was administered IP once daily for 4 days in a dose of $3.2 \mathrm{mg} / \mathrm{kg}$. (+)-MK-801 (Merck Sharp and Dohme, Inc.) was dissolved in saline solution. A dose of $0.18 \mathrm{mg} / \mathrm{kg}$ of $\mathrm{MK}-801$ was administered IP once daily $30 \mathrm{~min}$ prior to the injection of phencyclidine.

\section{Procedure}

Rats were randomly divided into five groups. Groups 1 and 2 were injected with either saline or phencyclidine and tested in the Digiscan system daily for 4 consecutive days. Locomotor activity and stereotypy of group 1 were assessed immediately following injection of saline, and locomotor activity and stereotypy of group 2 were assessed immediately following injection of $3.2 \mathrm{mg} / \mathrm{kg}$ phencyclidine given IP. The animals' activity was monitored continuously for the next 120 min. Data were accumulated in 10-min blocks throughout the 120-min period.

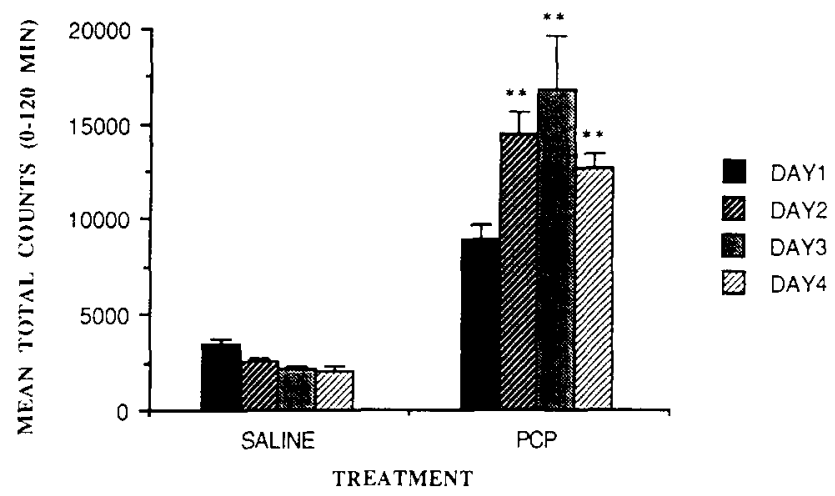

FIG. 1. Locomotor activity of rats treated with either phencyclidine or saline in the laboratory over 4 consecutive days. Each bar represents the mean total activity counts in $120 \mathrm{~min} \pm \mathrm{SE}$ for six rats. ${ }^{* *} p$ $<0.01$ compared with locomotor activity on day 1 .

Rats in groups 3, 4, and 5 received daily injections in the rodent facility for 3 consecutive days. Group 3 received saline and group 4 received $3.2 \mathrm{mg} / \mathrm{kg}$ of phencyclidine. Group 5 received $0.18 \mathrm{mg} / \mathrm{kg}$ of $\mathrm{MK}-801$, followed $30 \mathrm{~min}$ later by 3.2 $\mathrm{mg} / \mathrm{kg}$ phencyclidine. On the fourth day, rats were brought to the laboratory and tested in the Digiscan system immediately after injection of $3.2 \mathrm{mg} / \mathrm{kg}$ phencyclidine. Motor activity was monitored the same as with the other two groups.

\section{RESULTS}

Acute administration of $3.2 \mathrm{mg} / \mathrm{kg}$ IP of phencyclidine produced a marked increase in locomotor activity (Fig. 1) and stereotypy (Fig. 2). Although daily saline injection decreased locomotor activity, daily administration of $3.2 \mathrm{mg} / \mathrm{kg}$ IP phencyclidine resulted in an enhanced locomotor stimulant effect over 4 days. The difference in locomotor activity between the first and fourth injection was subjected to a correlated $t$-test, which indicated a statistically significant increase $(t=3.4963, p<0.01)$. Daily administration of phencyclidine also potentiated stereotypy progressively over the 4 days. The difference in stereotypy following the first compared to

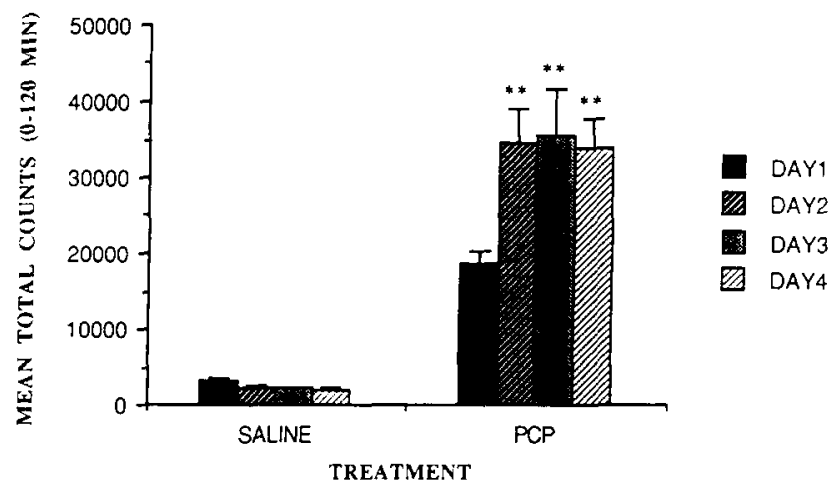

FIG. 2. Stereotypy of rats treated with either phencyclidine or saline in the laboratory over 4 consecutive days. Each bar represents the mean total stereotyped activity counts $\pm \mathrm{SE}$ in $120 \mathrm{~min}$ for six rats. ${ }^{* *} p<0.01$ compared with stereotypy on day 1 . 
the fourth injection was statistically significant $(t=4.3419$, $p<0.01$ ).

There was no difference in locomotor activity and stereotypy between the first injection of $3.2 \mathrm{mg} / \mathrm{kg}$ IP phencyclidine to rats in group 2 and to rats in group 3 treated with saline in the rodent facility. Therefore, these two groups were combined as an acute phencyclidine group (Acute-PCP in Fig. 36). A one-way ANOVA with multiple comparison was used to evaluate the differences in locomotor activity among the acute phencyclidine group, group 4 treated with three daily injections of phencyclidine in the home cage in the rodent facilities (homecage-PCP in Fig. 3), and group 5 treated with MK-801 followed by phencyclidine (MK-801 + PCP in Fig. 3). Both the Homecage-PCP and MK-801 + PCP groups showed significantly greater locomotor activity during the test session on day 4 compared with the Acute-PCP group, $F(2,19)=$ $8.2892, p \leq 0.01$. Furthermore, rats in both Homecage-PCP and MK-801 + PCP groups showed an enhanced locomotor stimulant effect of PCP as much as, or even greater than, that of rats treated with four daily injections of phencyclidine in the laboratory (Chronic-PCP in Fig. 3). However, the differences in locomotor activity among the Homecage-PCP, MK801 + PCP, and Chronic-PCP groups were not significant, as indicated in a separate one-way ANOVA. The differences in stereotypy among the Acute-PCP, Homecage-PCP, and MK-801 + PCP groups were also significant based on a oneway ANOVA with multiple comparison, $F(2,19)=4.2163$, $p<0.05$. Both the Homecage-PCP and MK-801 + PCP groups showed significantly greater stereotypy than the AcutePCP groups (Fig. 4), A separate one-way ANOVA revealed that the differences in stereotypy among the Chronic-PCP, Homecage-PCP, and MK-801 + PCP groups were not significant.

The locomotor activity and stereotypy of the ChronicPCP, Homecage-PCP, and MK-801 + PCP groups were compared further, and the data are shown in 30-min subsessions over the 2 -h test session in Figs. 5 and 6 . The mean locomotor activity counts of the Homecage-PCP and MK$801+$ PCP groups were higher than that of the Chronic-PCP groups over the 2-h test session (Fig. 5). However, a two-way

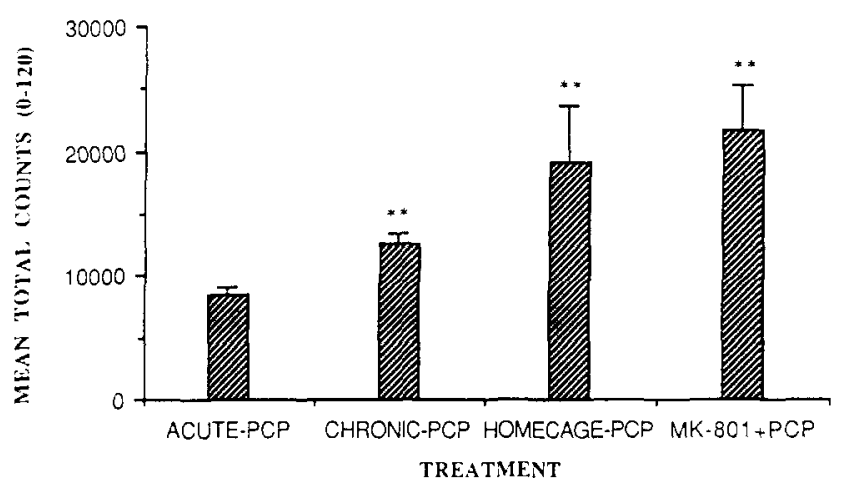

FIG. 3. Effect of phencyclidine on locomotor activity of rats with different drug histories. Acute-PCP: rats received no prior phencyclidine injection. Chronic-PCP: rats received three prior phencyclidine injections in the laboratory. Homecage-PCP: rats received three prior phencyclidine injections in the rodent facility. MK-801 + PCP: rats received three prior injections of MK-801 followed by phencyclidine. Each bar represents the mean total activity counts \pm SE in $120 \mathrm{~min}$ for five to 11 rats. ${ }^{* *} p<0.01$ compared with Acute-PCP group.

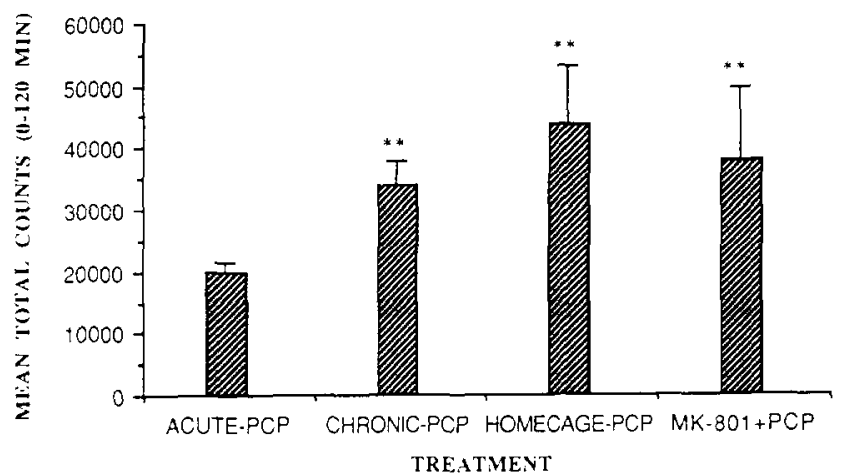

FIG. 4. Effects of phencyclidine on stereotypy of rats with different drug histories. Groups are the same as in Fig. 3. Each bar represents the mean total stereotypy counts $\pm S E$ in 120 min for five to 11 rats. ${ }^{* *} p<0.01$ compared with the Acute-PCP group.

ANOVA with repeated measures showed the differences were not significant. A separate two-way ANOVA with repeated measures suggested that there were no significant differences in stereotypy among the Chronic-PCP, Homecage-PCP, and MK-801 + PCP groups over the 2-h test session (Fig. 6).

\section{DISCUSSION}

Spontaneous behavior, including locomotor activity, rearing, stereotypy, and ataxia, induced by single and repeated administration of phencyclidine has been studied for the past 10 years. The effects following single doses are more consistent than those of chronic administration. Acute administration of phencyclidine $(1.0-5.0 \mathrm{mg} / \mathrm{kg})$ induces a dose-related increase in locomotor activity, sniffing, repetitive head movements, nonobject directed mouth movements, and ataxia (5). A linear dose-response effect has been found for measures of locomotor activity, stereotypy, and ataxia through moderate dose levels $(2-6 \mathrm{mg} / \mathrm{kg})$, but only ataxia ratings continued to increase, showing a linear relationship through the higher doses (2). With respect to rearing activity, however, acute injection of phencyclidine produces little or no effect $(5,7)$. Chronic administration of phencyclidine results in an enhanced locomotor stimulant effect $(2,5-7,19)$. Chronic injection of phencyclidine was reported to produce sensitization to rearing and stereotypy only in some of these studies. Our results confirm the existing literature that acute phencyclidine administration produced an increase in locomotor activity and stereotypy, and that sensitization to locomotor activity developed following four daily injections. Furthermore, sensitization to stereotypy also developed over four daily injections of phencyclidine in our study. This is consistent with our preliminary unpublished data, in which increased repetitive head movements over four daily injections of phencyclidine were observed. In the preliminary study, rats were placed in cages marked with a touchline set $12 \mathrm{~cm}$ above the cage floor. Immediately after injection of phencyclidine, rats were observed through a one-way mirror for $120 \mathrm{~min}$ by one rater to measure rearing, locomotor activity, and stereotypy. One count of rearing was recorded when raised rats' heads crossed the touchline with both forepaws leaving cage floor. The results showed that four daily injections of phencyclidine also produced sensitization to rearing, in addition to locomotor activity and stereotypy. 


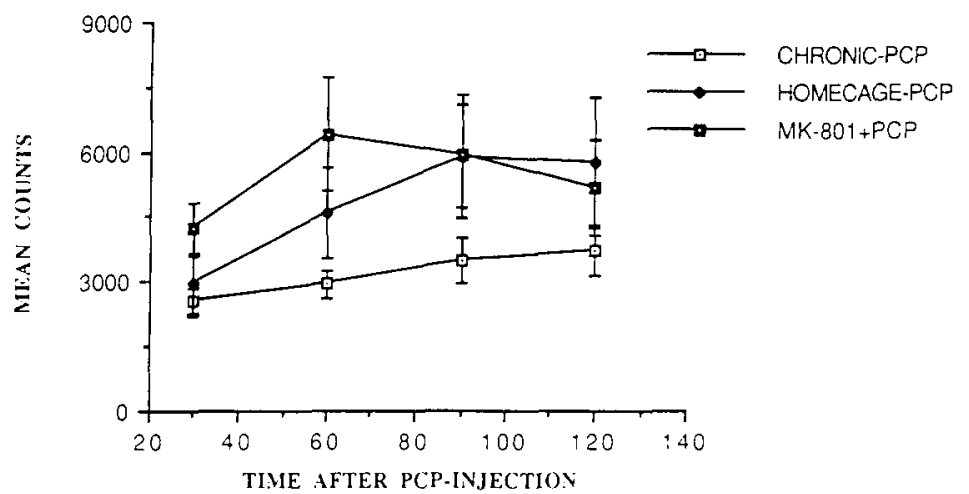

FIG. 5. Locomotor activity of the Chronic-PCP, Homecage-PCP, and MK$801+$ PCP groups in 30-min blocks over the 2-h test session. Each point represents the mean activity counts in $30 \mathrm{~min} \pm \mathrm{SE}$ for five to six rats.

Several studies have reported conditioning of the locomotor stimulant effects of psychomotor stimulants $(3,14,16,21)$. In these studies, the unconditioned stimulus was an injection of a drug that produced hyperactivity, and the conditioned stimulus was placing the animal in a testing cage or chamber, which was paired with the drug injection. As a result of pairing, placing the animal in the testing environment was found capable of producing hyperactivity similar to that elicited by the drug. Conditioned locomotor activity has been demonstrated by Tilson and Rech (20) for amphetamine sensitization of locomotor activity. Segal (17) has argued that drug-environment conditioning cannot account for behavioral sensitization to amphetamine. It has been demonstrated that it is not necessary to treat animals with amphetamine in the testing environment to produce sensitization (1). Amphetamine and phencyclidine are both proposed to alter spontaneous behavior through dopaminergic mechanisms (5). However, chronic daily injection of amphetamine sensitized animals to the locomotor stimulating effects of phencyclidine, but chronic daily phencyclidine treatment decreased the locomotor response to a challenge injection of amphetamine. Thus, an asymmetric cross-sensitization occurs between amphetamine and phencyclidine. These findings suggest significant differences in the neural mechanisms underlying the effects of daily administration of phencyclidine and amphetamine. Although amphetamine sensitization is different from daily phencyclidine sensitization, our results that daily injection of phencyclidine in the rodent facility produced sensitization during the test in laboratory suggested that drug-environment conditioning is not necessary for the development of behavioral sensitization to phencyclidine.

It has been suggested that behavioral sensitization resembles long-term potentiation (LTP), a long-lasting increase of synaptic efficacy $(9,10,21)$. Both phenomena involve persistent changes in neuronal responsiveness. It is well established that activation of the $N$-methyl-D-aspartate (NMDA) class of glutamate receptors is required for the induction of hippocampal LTP, since administration of NMDA antagonists, such as AP5 or MK-801, block the induction but not maintenance of LTP $(4,13)$. It has also been demonstrated that the induction of behavioral sensitization to amphetamine and cocaine requires activity of NMDA receptors because the induction of

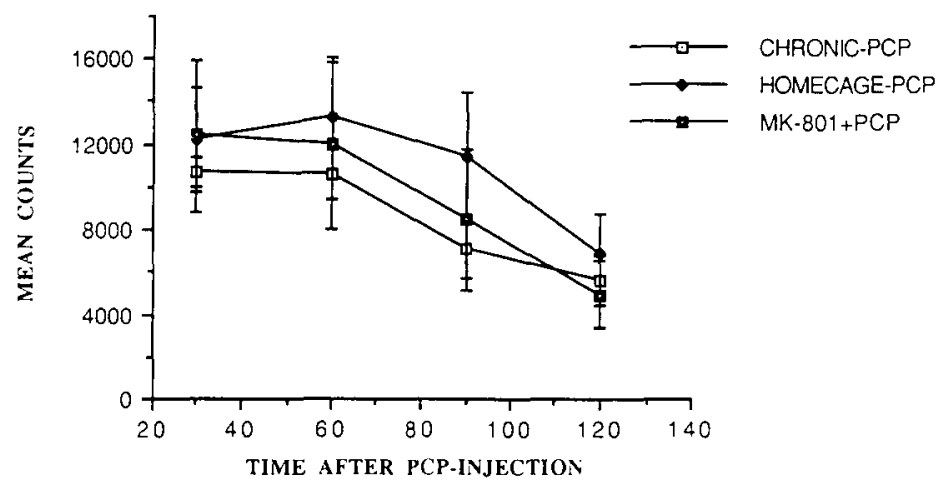

FIG. 6. Stereotypy of the Chronic-PCP, Homecage-PCP, and MK-801 + PCP groups in 30-min blocks over the 2-h test session. Each point represents the mean stereotypy counts in $30 \mathrm{~min} \pm \mathrm{SE}$ for five to six rats. 

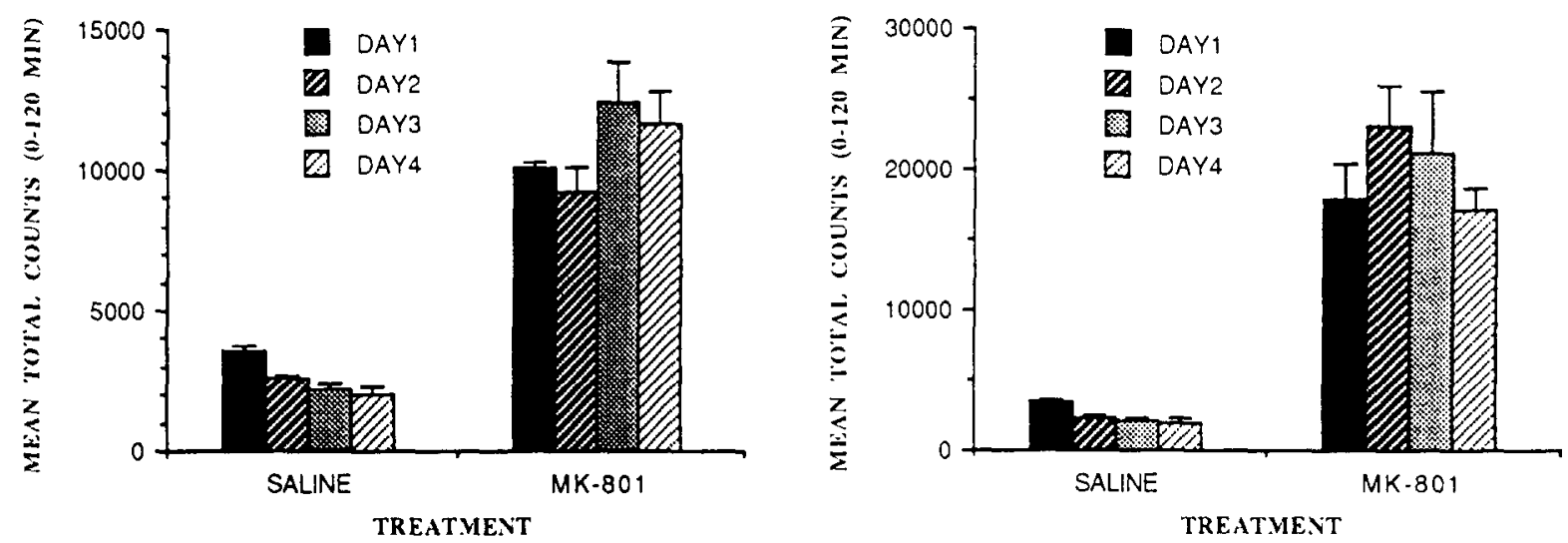

FIG. 7. Locomotor activity (left panel) and stereotypy (right panel) of rats treated with either MK-801 or saline over 4 consecutive days. Each bar represents the mean total counts in $120 \mathrm{~min} \pm$ SE for five rats.

behavioral sensitization is blocked by MK-801 (8-10,21). Our results indicate that phencyclidine sensitization is not blocked by MK-801. There are two possible explanations. First, not all behavioral sensitization involves NMDA receptor activation, just as not all types of LTP involve NMDA receptors. Second, because both phencyclidine and MK-801 are antagonists at the same channel site of the NMDA receptor, it is possible that they both induce behavioral sensitization through identical mechanisms that allows one to substitute for the other. Wolf and Khansa (21) have shown that repeated MK-801 administration produces behavioral sensitization to MK-801 although it blocks sensitization to amphetamine. Thus, the enhanced stimulant effects of phencyclidine in our study may be due to cross-sensitization from MK-801 to phencyclidine. However, our ongoing experiments suggest that this is not the case. When the dose of $0.18 \mathrm{mg} / \mathrm{kg} \mathrm{MK}-801$ was administered alone, it produced enhanced locomotor activity and stereotypy (Fig. 7). However, four daily injection of 0.18 $\mathrm{mg} / \mathrm{kg} \mathrm{MK-801} \mathrm{did} \mathrm{not} \mathrm{induce} \mathrm{sensitization} \mathrm{to} \mathrm{either} \mathrm{locomo-}$ tor activity or stereotypy (Fig. 7). Furthermore, pretreatment with $0.18 \mathrm{mg} / \mathrm{kg} \mathrm{MK}-80130 \mathrm{~min}$ prior to phencyclidine injection significantly reduced the locomotor stimulant effect and stereotypy of the phencyclidine (Fig. 8), and produced severe ataxia (data not shown) over 4 days. When phencyclidine was administered alone on day 5 , rats showed sensitization to both its locomotor stimulant effect and stereotypy. When MK-801 was administered alone on day 6 , rats did not show sensitization to either the locomotor stimulant effect or stereotypy of MK-801.

In summary, daily injections of phencyclidine for 4 days resulted in sensitization to both locomotor activity and stereotypy. Both the Homecage-PCP and MK-801 + PCP groups showed enhanced locomotor stimulant effects of phencyclidine and potentiated stereotypy as much as, or even greater than, that of the Chronic-PCP group. Therefore, daily homecage injection of phencyclidine also produced sensitization. Furthermore, MK-801 failed to block sensitization to phencyclidine.

\section{ACKNOWLEDGEMENT}

Supported in part by NIDA Grant DA-01531.
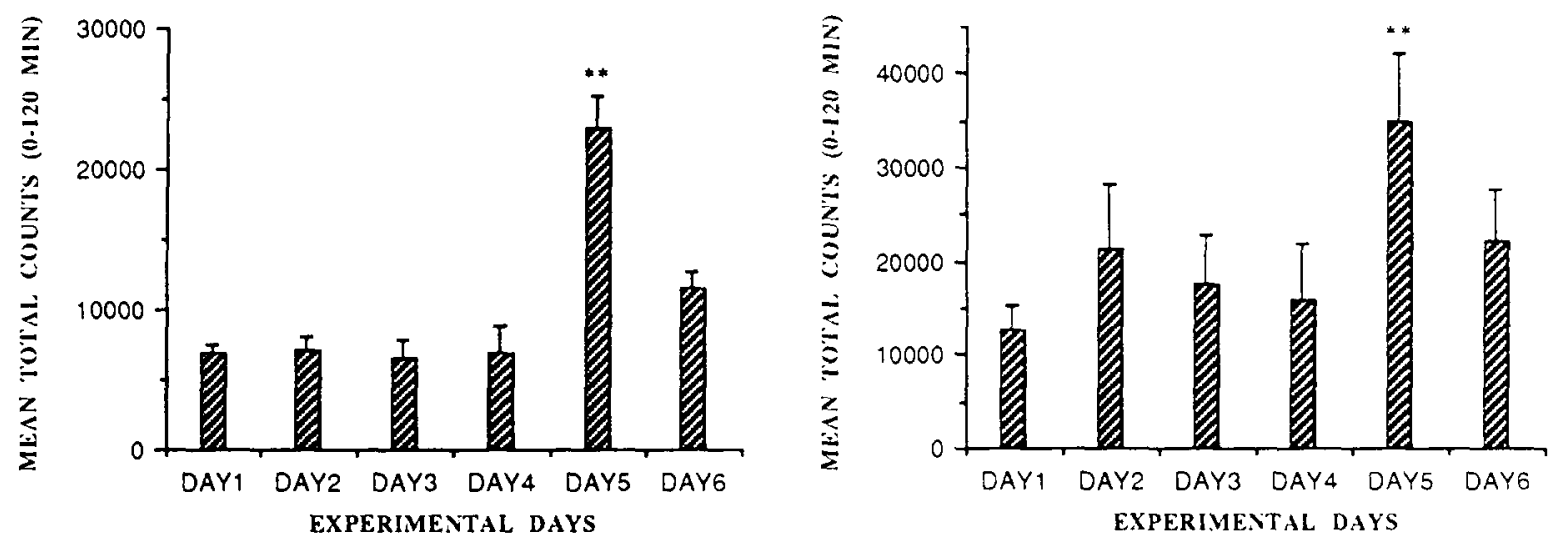

FIG. 8. Locomotor activity (left panel) and stereotypy (right panel) of rats treated with PCP following 30-min pretreatment of MK-801 over 4 consecutive days. On day 5 rats were treated with PCP alone. On day 6 rats were treated with MK-801 alone. Each bar represents the mean total counts in $120 \mathrm{~min} \pm \mathrm{SE}$ for five rats. ${ }^{* *} p<0.01$ compared with the Acute-PCP group. 


\section{REFERENCES}

1. Browne, R.; Segal, D. S. Metabolic and experimental factors in the behavioral response to repeated amphetamine. Pharmacol. Biochem. Behav. 6:545-552; 1977.

2. Castellani, S.; Adams, P. M. Acute and chronic phencyclidine effects on locomotor activity, stereotypy and ataxia in rats. Eur. J. Pharmacol. 73:143-154; 1981.

3. Ellinwood, E. H. Accidental conditioning with chronic methamphetamine intoxication: Implications for a theory of drug habituation. Psychopharmacology (Berlin) 21:131-138; 1971.

4. Gilbert, M. E.; Mack, C. M. The NMDA antagonist, MK801, suppresses long-term potentiation, kindling, and kindlinginduced potentiation in the perforant path of the unanesthetized rat. Brain Res. 519:89-96; 1990.

5. Greenberg, B. D.; Segal, D. S. Acute and chronic behavioral interactions between phencyclidine (PCP) and amphetamine: Evidence for a dopaminergic role in some PCP-induced behaviors. Pharmacol. Biochem. Behav. 23:99-105; 1985.

6. Greenberg, B. D.; Segal, D. S. Evidence for multiple opiate receptor involvement in different phencyclidine-induced unconditioned behaviors in rats. Psychopharmacology (Berlin) 88:44-53; 1986.

7. Iwamoto, E. T. Comparison of the pharmacological effects of $\mathrm{N}$-allylnormetazocine and phencyclidine: Sensitization, cross-sensitization, and opioid antagonist activity. Psychopharmacology (Berlin) 89:221-229; 1986.

8. Karler, R.; Calder, L. D.; Chaudhry, I. A.; Turkanis, S. A. Blockade of "reverse tolerance" to cocaine and amphetamine by MK-801. Life Sci. 45:599-606; 1989.

9. Karler, R.; Calder, L.D.; Turkanis, S.A. DNQX blockade of amphetamine behavioral sensitization. Brain Res. 552:295-330; 1991.

10. Karler, R.; Chaudhry, I. A.; Calder, L.D.; Turkanis, S. A. Amphetamine behavioral sensitization and the excitatory amino acids. Brain Res. 537:76-82; 1990.

11. Karler, R.; Turkanis, S. A.; Partlow, M. M.; Calder, L. D. Cal- cium channel blockers and behavioral sensitization. Life Sci. 49: $165-170 ; 1991 b$.

12. Leccese, A. P.; Marquis, K. L.; Mattia, A.; Moreton, J. E. The anticonvulsant and behavioral effects of phencyclidine and ketamine following chronic treatment in rats. Behav. Brain Res. 22: 257-264; 1986 .

13. Muller, D.; Joly, M.; Lynch, G. Contributions of quisqualate and NMDA receptors to the induction and expression of LTP. Science 242:1694-1697; 1988.

14. Pickens, R.; Dougherty, J. A. Conditioning of the activity effects of drugs. In: Thompson, T. I.; Pickens, R., eds. Stimulus properties of drugs. New York: Appleton-Century-Crofts; 1971.

15. Robinson, T. E.; Becker J. B. Enduring changes in brain and behavior produced by chronic amphetamine administration. A review and evaluation of animal models of amphetamine psychosis. Brain Res. Rev. 11:157-198; 1986.

16. Schiff, S. R. Conditioned dopaminergic activity. Biol. Psychiatry $17: 135-154 ; 1982$.

17. Segal, D. S. Behavioral and neurochemical correlates of repeated $d$-amphetamine administration. Adv. Biochem. Psychopharmacol. 13:247-262; 1975.

18. Smith, R. D.; Biggs, C.; Nroulis, G.; Brinkman, S. Effects of chronic administration of phencyclidine on stereotyped and ataxic behaviors in rats. Life Sci. 28:1163-1174; 1981.

19. Stergeon, R. D.; Fessler, R. G.; London, S. F.; Meltzer, H. Y. Behavioral effects of chronic phencyclidine administration in rats. Psychopharmacology (Berlin) 76:52-56; 1982.

20. Tilson, H. A.; Rech, R. H. Conditioned drug effects and absence of tolerance to $d$-amphetamine produced motor activity. Pharmacol. Biochem. Behav. 1:149-153; 1973.

21. Wolf, M. E.; Khansa, M. R. Repeated administration of MK-801 produces sensitization to its own locomotor stimulant effects but blocks sensitization to amphetamine. Brain Res. 562:164-168; 1991. 